\title{
Paediatric Dentistry and Prevention from Teenage Pregnancy
}

\author{
Ana Ofelia Ivars* \\ Private Clinic Children and Teenagers Dental Care, National University of Cordoba, Argentina
}

*Corresponding author: Ana Ofelia Ivars, Private Clinic Children and Teenagers Dental Care, National University of Cordoba, Argentina

Received: 嗢 September 24, 2019

Published: 眥 October 10, 2019

\begin{abstract}
Medical specialties have paid little attention to the teenage stage, including Dentistry. If to this we add the teen pregnancy trends due to economic, social or cultural circumstances, the results are young women with a high prevalence of caries, periodontal disease and early tooth loss. etc.

Objective: To detect teenagers at risk through different educational institutions such as churches, health centers, sports clubs,

Situation Analysis: The field study revealed a worrying number of adolescents who drop out of school or job due to pregnancy at a young age.

Intervention Strategies: Three different levels of prevention were stablished

a) Primary prevention: measures intended to prevent teenage pregnancy.

b) Secondary prevention: measures adopted when there was evidence of an ongoing pregnancy.

c) Tertiary prevention: measures taken to promote school reinsertion and reintegration into the labor market.

Results: Teachers, doctors, dentists, obstetricians, physical therapists, neonatologists and pediatricians worked in a multi and interdisciplinary way in order to educate and promote healthy living, and to avoid risk situations in this age group.
\end{abstract}

Keywords: Teenage pregnancy; Caries; Oral health; Education; Prevention

Abbreviations: UNFPA: United Nations Population Fund in Argentina; UNICEF: United Nations International Children's Emergency Fund

\section{Introduction}

The topic to be developed is about an issue which has arisen in important sectors of young people from Chaco. Around sixteen million of young women between the ages of fifteen and nineteen give birth each year - roughly eleven percent of all births worldwide. Complications related to childbirth and pregnancy is the main cause of death among adolescent girls, especially in developing countries. In Latin America, ten percent of girls aged fifteen to nineteen are mothers. In Argentina, the number of teenage pregnancies has increased since 2001, representing a sixteen percent of pregnancies. The percentage recorded in some areas such as the Argentinian northeast and west was twenty five percent [1]. Teenage motherhood and fatherhood are more frequent among young, poor people who have a lower educational level.
Eighty percent of teenagers who don't have children attend school regularly, while twenty five percent of teenagers who have children don't. The number of teenage mothers with incomplete primary education trebles the number of those with incomplete secondary education [2]. The national legislative framework contains rules as the Law 25.673 which ensures that young people have the right to access to sexual and reproductive health. The Law 26.150 states that individuals have the right to receive sexual integral education from elementary to superior level studies. The Laws 25.58 and 25.273 provide that the continued attendance at school of pregnant students is guaranteed. Carlos Dabalioni, Director of Children and Adolescents Department of La Plata City Hall, Buenos Aires, has stated that, although in some cases pregnancy is the result of misinformation, it goes beyond mere teaching teenagers how to 
take care of themselves; because the problem is, in many cases, the lack of social and family support. To many women, having a child is their only asset, the chance to have the family they didn't have when they were younger, the only way to keep their partners or give the baby all they lacked. When that kind of support is missing, there is no point trying to teach young women how to take care of themselves. UNICEF's Regional Office for Latin America and the Caribbean has claimed that "UNICEF is committed to focusing its efforts on the phases of adolescence as the opportunity to develop individual skills and abilities in favorable and safe surroundings, so as to enable the adolescent to contribute to and participate in the family, school, community and society" [3].

\section{Adolescence Stages}

Adolescence can be divided into three different stages, which entails different ways to deal with pregnancy:

\section{Early adolescence (10 -13 years old):}

a) Strong connection with the mother.

b) Denial of pregnancy.

c) Depression and social isolation caused by unplanned maternity.

d) The father is absent from the mother's plans and decisions.

Middle adolescence (14-16 years old):

a) The mother sees the child as her possession and as an instrument to show independence from her parents.

b) Ambivalent attitude: blame and pride.

c) The father is given a more important role. He's considered as a hope for the future.

Late adolescence (17-19 years old):

a) Adaptation to the reality impact.

b) Feelings of motherhood.

c) Search for affection, commitment, dedication from the baby's father.

d) Mother's desire to have a settled life with her partner.

It is important to highlight that a teenage pregnant won't reach mental and emotional maturity earlier than expected. She will behave in accordance with the stage she is going through [4].

\section{Consequences of an Unplanned Pregnancy}
a) High risk of maternal mortality
b) Higher possibility of premature births
c) Risk of having a child with low birth weight
d) Difficulties in completing studies and having a life project.
At a global level, increased morbidity during teenage pregnancy is caused by:
a) Abortion
b) Anaemia
c) Urinary infection
d) Asymptomatic bacteriuria
e) Gestational hypertension
f) Preeclampsia - Eclampsia
g) Little weight gain
h) Maternal malnutrition
i) Haemorrhage associated with placental conditions
j) Preterm birth
k) Preterm rupture of the membranes
l) Cephalopelvic disproportion
m) Caesarean section

\section{Levels of Prevention}

\section{Primary Prevention}

The first level concerns the application of measures to prevent unplanned teenage pregnancy.

a) Information distribution about gradual and sequential reproductive physiology not only in school but also in all areas.

b) Appropriate use of mass media.

c) Fostering strong parents/school-children communication and collective reflection on adolescence issues.

d) Training of people who often deal with high-risk young people who quit school or job in order to help them reintegrate fully into society.

\section{Secondary Prevention}

The second level concerns the actions that should be taken if there is an existing pregnancy.

a) Activities to improve maternal health through the promotion of pre-natal and post- partum health care programmes for teenage mothers.

b) Assistance should be given to the teenage father, helping him to assume his social role.

c) Psychological support and information should be provided to young mothers who decide to place their children for adoption.

\section{Tertiary Prevention}

The third level concerns the monitoring of the mother/fatherchild bond and the support and fostering the parents' reinsertion in the labor market. At an educational level, the emphasis is placed on the relevance of speaking about sexual and reproductive health with teenagers and their friends, parents, teachers and trustworthy 
adults, teaching teenagers how to resist social pressures and delay onset of sexual activity to prevent sexually transmitted diseases and unplanned pregnancies, teaching teenagers to support those who decide not to have sexual relations (they have to be prepared to say no and act firmly when faced with risk situations or threats), raising awareness about the importance of condom use during intercourse to ensure their protection, keeping reminding young people that they should avoid drinking alcohol or taking drugs when they are with their partners, so that they can make right and responsible decisions regarding sexuality and sexual behaviors, and promoting safe, healthy and responsible sexuality. Teenage pregnancy can be prevented, not cured. If an unplanned pregnancy happens, parents play a vital supportive role. They should teach their children to behave responsibly and confront life difficulties.

\section{Caries Prevention during Pregnancy}

It is well known that teeth and gums are affected during pregnancy since hormonal changes have a great impact on women's gums. These may bleed spontaneously, be itemized and red, causing halitosis. There is a higher risk of tooth decay during pregnancy because of nausea, vomiting, reduced saliva $\mathrm{pH}$ and secretion, anxiety, and higher consumption of sweets. Caries can be prevented by adopting a good oral hygiene (for at least 2 minutes), brushing the teeth three times or more per day, consuming calcium-rich foods (such as milk, yogurt, cheese), proteins (meat, eggs), vitamins and minerals (fruits, vegetables, cereals, beans), avoiding sugary foods and drinks, and visiting the dentist once each trimester during pregnancy. Babies are born free from bacteria that cause tooth decay. Bacteria are spread through saliva when the mother kisses the baby in the mouth, or cleans the bottle or the pacifier, also when the baby's first teeth appear. Babies shouldn't sleep with the bottle in the mouth. The sugar contained in milk together with the bacteria produce an acid that can eat through the teeth, leading to dental enamel damage. To eliminate or reduce caries risk factors in the baby is necessary to use a mouthwash-soaked gauze to clean inside the baby's mouth after breastfeeding or drinking from a baby bottle, brushing their teeth from the first moment they appear and visiting the dentist with the baby so they can monitor your child's oral health from birth and every six months.

\section{Materials and Methods}

A Mother-Child Programmed was implemented in health centers, with the multidisciplinary professionals' participation. Dental care and prevention were taught through games, as well as pre- birth gym. Efforts were made to empower individuals and government agencies, civil associations, academic institutions and the private sector.

\section{Results and Discussion}

The present research is based on data field extracted from the UNFPA, an international cooperation organism for development formed in 1969. It has been running in Argentina since 2003, promoting women, men and children's rights to enjoy a healthy life and equality of opportunities [5]. In 2018, the UNFPA struggled to achieve 3 transforming, ambitious goals which promise to change every man, woman and child's life: to put an end to the family planning unsatisfied need, to the gender violence [6] and to the preventable maternal death [7].

\section{Conclusion}

Early pregnancy and motherhood are strictly linked to human right issues. A pregnant child is pushed to drop out school. In all regions of the world, poor children with lack of education and living in rural areas are at risk of getting pregnant. Pregnancy can have devastating effects on the young mother's health. Many teenagers are not physically prepared to get pregnant or deliver; therefore, they are more vulnerable to complications. Besides, teenage pregnancy has tremendous costs in girls' education and incomes potential. In Argentina, efforts are being made to prevent teenage pregnancy, trying to change factors such as inequality of gender, poverty, sexual violence and coercion. Such an approach must include provision of suitable, integral sexual education for every young man and woman, as well as investment in girls' education and measures to guarantee the access to information about sexual and reproductive health and services to facilitate young people's life choices.

\section{References}

1. Gómez P (2011) Factores relacionados con el embarazoyla maternidad en menores de 15 años en América Latina y El Caribe. Lima: Federación Latinoamericana de Sociedades de Obstetricia y Ginecología.

2. UNICEF (2011) Estado mundial de la infancia- La adolescencia Una época de oportunidades, Fondo de las Naciones Unidas para la Infancia, p. 2.

3. UNICEF (2014) The State of the World's Children 2014 in Numbers. Every Child Counts: Revealing disparities, advancing children's rights. Nueva York, USA.

4. UNFPA (2015) Girlhood, Not Motherhood: Preventing Adolescent Pregnancy. Published by the United Nations Population Fund, New York, USA, p. 7.

5. UNFPA (2016) Fecundidad y Maternidad Adolescente en el Cono Sur: Apuntes para la Construcción de una Agenda Común p. 9.

6. UNFPA Fondo de Población de las Naciones Unidas. El embarazo en la adolescencia.

7. Conde-Agudelo A (2005) Maternal-perinatal morbidity and mortality associated with adolescent pregnancy in Latin America: Cross Sectional study. American Journal of Obstetrics and Gynecology 192: 342-349. 
This work is licensed under Creative Commons Attribution 4.0 License

To Submit Your Article Click Here: $\quad$ Submit Article

DOI: $10.32474 /$ IPDOAJ.2019.03.000161

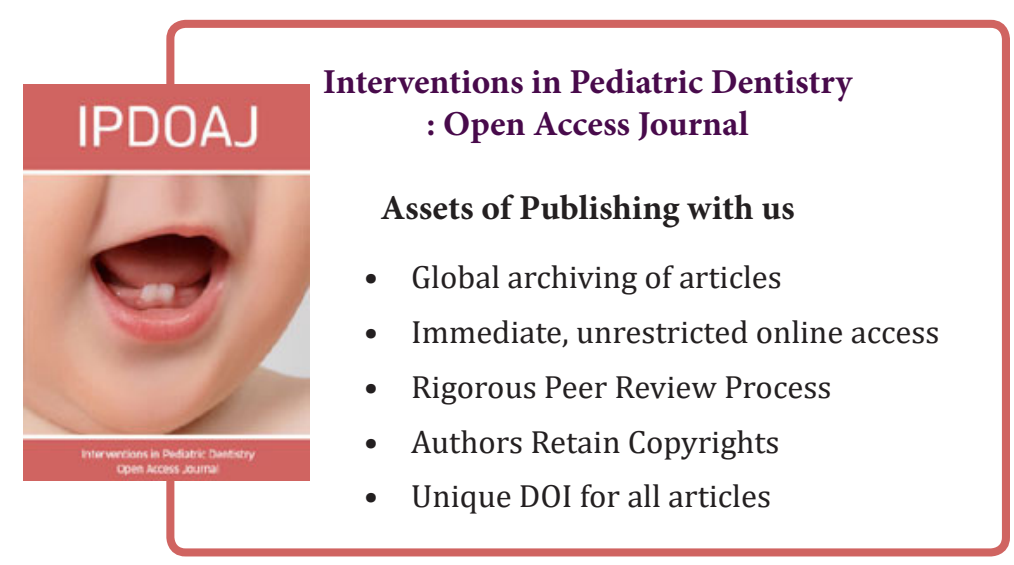

